\title{
Psychiatric nurse practitioners' experiences of working with mental health care users presenting with acute symptoms
}

\author{
Authors: \\ Jacobs K. Ngako ${ }^{1,2}$ \\ Elsie S.J. van Rensburg ${ }^{1}$ \\ Sanah M.L. Mataboge ${ }^{1}$ \\ ${ }^{1}$ Department of Nursing \\ Science, University of \\ Pretoria, South Africa \\ ${ }^{2}$ Alcohol and Drug Abuse \\ Research Unit, South African \\ Medical Research Council, \\ South Africa \\ Correspondence to: \\ Jacobs Ngako \\ Email: \\ Kgalabi.ngako@mrc.ac.za \\ Postal address: \\ P.O. BOX 1751, Silverton \\ 0127, South Africa \\ Dates: \\ Received: 17 Aug. 2011 \\ Accepted: 18 Dec. 2011 \\ Published: 30 May 2012 \\ How to cite this article: \\ Ngako, J.K., Van Rensburg, \\ E.S.J. \& Mataboge, S.M.L., \\ 2012, 'Psychiatric nurse \\ practitioners' experiences of \\ working with mental health \\ care users presenting with \\ acute symptoms', Curationis \\ 35(1), Art. \#44, 9 pages. \\ http://dx.doi.org/10.4102/ \\ curationis.v35i1.44
}

C 2012. The Authors. Licensee: AOSIS OpenJournals. This work is licensed under the Creative Commons Attribution License.
Psychiatric nurse practitioners (PNPs) working with mental health care users presenting with acute symptoms work in a complex environment. This environment is characterised by mental health care users who may present with a history of violence, sexual assault and substance misuse.

The objectives of this study were twofold: firstly, to explore and describe the experiences of PNPs working with mental health care users (MHCUs) presenting with acute symptoms; and secondly, to make recommendations for the advanced PNPs to facilitate promotion of the mental health of PNPs with reference to nursing practice, research and education.

A qualitative, explorative, descriptive and contextual design was used. The target population was PNPs working with MHCUs presenting with acute symptoms in a public mental health care institution in Gauteng. Data were collected by means of four focus group interviews involving 21 PNPs. The researcher made use of drawings, naïve sketches and field notes for the purpose of data triangulation. Data were analysed in accordance with Tesch's method of open coding.

The three themes that emerged were: PNPs experienced working with these MHCUs as entering an unsafe world where care became a burden; they experienced negative emotional reactions and attitudes towards these MHCUs that compromised quality nursing care; and they made a plea for a nurturing environment that would enhance quality nursing care.

The PNPs suggest skills and competency development, organisational support, and a need for external resources. Creation of a positive environment and mobilisation of resources as well as the identification and bridging of obstacles are essential in the promotion of the overall wellbeing and mental health of PNPs.

\section{Introduction}

Mental health care within public health care institutions includes health care provision to mental health care users (MHCUs) presenting with acute and chronic symptoms and possibly an unstable mental health status. These acute symptoms of mental illness may include hallucinations, delusion and lack of insight into their mental health status (Waldheter et al., 2005:610). Acute symptoms may also present with increased levels of violence and sexual assault (Richards et al. 2006:34).

Psychiatric nurse practitioners (PNPs) working with MHCUs presenting with acute symptoms work in a complex environment. Admission of MHCUs presenting with acute symptoms takes place under traumatic and distressing circumstances and at a time when these individuals are unstable (Deacon, Warne \& McAndrew 2006:752). In a study by Chaplin, McGeorge and Lelliott (2006:445) on a national audit of violence in psychiatric wards, PNPs reported that they had been subjected to violence and threats from MHCUs. Mackay, Paterson and Cassels (2005:465) hold that in some units PNPs work with MHCUs presenting with acute symptoms who are at risk of suicide and self-harm.

The demands of working with MHCUs presenting with acute symptoms may contribute to PNPs experiencing occupational stress, burnout and emotional exhaustion (Robinson, Clements \& Land 2003:34). PNPs working with MHCUs presenting with symptoms of aggression and violence may experience fear, anger, frustration, helplessness and job dissatisfaction (Bimenyimana et al. 2006:8). These negative experiences can result in PNPs finding that they are unable to work effectively with MHCUs presenting with acute symptoms. This study explores and describes the experiences of PNPs working with MHCUs presenting with acute symptoms, and make recommendations to facilitate the mental health of PNPs when working with these individuals. 


\section{Problem statement}

MHCUs presenting with acute symptoms make challenging demands on the PNPs who work with them (Fourie et al. 2005:135). These demands include maintaining unit safety, retaining supportive relationships with MHCUs presenting with acute symptoms, and attending to their emotional and physical needs.

When supervising these individuals, PNPs' own mental health may be affected negatively; this can result in absenteeism, low self-esteem, little (or no) job satisfaction and resignation (Humpel \& Caputi 2001:399). Unfortunately, according to Munro and Baker (2007:197) there is a lack of knowledge about the experiences of PNPs working with MHCUs presenting with acute symptoms. Consequently, it was deemed appropriate and necessary to explore this phenomenon in South Africa.

\section{Aim of the study}

The overall purpose of this study was to explore and describe PNPs' experiences of working with MHCUs presenting with acute symptoms in a public mental health care institution in Gauteng.

\section{Research objectives}

The objectives of this research were:

- to explore and describe PNPs' experience of working with MHCUs presenting with acute symptoms; and

- to make recommendations in terms of advanced PNPs to facilitate promotion of their mental health with reference to nursing practice, research and education.

\section{Definition of key concepts}

Acute symptoms: These may include hallucinations, delusion, violence, suicide risk, and the risk of harm to the self and others (Theodoridou et al. 2009:234). In this study 'acute symptoms' refer to the following symptoms presented by MHCUs: hallucinations, delusion, violence, risk of suicide, unacceptable sexual behaviour, risk of suicide and/or risk of harm to themselves or to others.

Closed ward: A restricted environment to provide MHCUs with care, treatment and rehabilitation services for the purpose of closer supervision and monitoring to minimise the risk of danger to self, others or property.

Experience: The Oxford English Dictionary (Soanes, Hawker \&Elliott 2006:261) defines experience as the 'practical contact with and observation of facts or events and knowledge or skill gained over time. In this study 'experience' will refer to the expressions of PNPs regarding working with MHCUs presenting with acute symptoms in a public mental health care institution in Gauteng.

Mental health: Uys and Middleton (2010:16) define 'mental health' as 'a state of well-being in which the individual realises his or her own abilities, can cope with the normal stresses of life, can work productively and fruitfully, and is able to make a contribution to his or her community.' For this study 'mental health' will refer to the state of well-being of the PNPs working with MHCUs presenting with acute symptoms, and their capacity to cope with their internal and external needs.

Mental health care user (MHCU): According to the South African Mental Health Care Act (Mental Health Care Act No. 17 of 2002:10), an MHCU is a person receiving care, treatment and rehabilitation services at a health establishment. In this study an MHCU will refer to a person receiving care, treatment and rehabilitation services in a specific public mental health care institution in Gauteng.

Open ward: A less restricted environment to provide MHCUs with care, treatment and rehabilitation services.

Psychiatric nurse practitioner (PNP): A qualified nurse who has been trained in the field of Psychiatric Nursing to provide care, treatment and rehabilitation to MHCUs (Mental Health Care Act No. 17 of 2002:10). In this study PNP will refer to a qualified registered nurse in Psychiatric Nursing, working with MHCUs presenting with acute symptoms in a specific mental health care institution in Gauteng.

\section{Significance of the study}

Knowledge gained could be used to facilitate the mental health of PNPs working with MHCUs presenting with acute symptoms with reference to nursing practice, education and research.

\section{Research method and design}

The research design is discussed under the following subheadings: qualitative design, explorative design, descriptive design and contextual design. In the research methods section the following are discussed: population and sampling, sampling criteria, the role of the researcher, data collection and data analysis.

\section{Design}

Polit and Beck (2008:765) define research design as the overall plan for addressing a research question, including specifications for enhancing the study's integrity. A qualitative, explorative, descriptive and contextual design was used to explore the topic in this study.

\section{Qualitative design}

Qualitative research is defined by Bowling (2002:435) as social research carried out in the field or natural setting and analysed largely in non-statistical ways. It is a method of naturalistic inquiry which is usually less obstructive and does not manipulate the research setting. Qualitative researchers aim to study people in their natural settings and collect naturally occurring data. Bowling (2002:352) adds that 
the focus is on the meanings that the participants in the study setting attach to their social world.

The strengths of qualitative research lie in people being studied in their natural setting, with in-depth data about the phenomenon under study gathered. It enables the researcher to gain better insight into the subjective feelings of participants. Qualitative research produces more in-depth, comprehensive information. It seeks a wide understanding of the entire situation. In this study the researcher involved research supervisors and an independent coder during data analysis. Parahoo (2006:397) states that involving another researcher ensures rigour in data analysis.

\section{Explorative design}

Explorative qualitative research begins with a phenomenon of interest and investigates the full nature of the phenomenon and the manner in which it is manifested. According to Polit and Beck (2008:21), exploratory qualitative research is designed to shed light on the various ways in which a phenomenon is manifested. This study focused on an exploration and description of the experiences of PNPs working with MHCUs presenting with acute symptoms.

\section{Descriptive design}

Descriptive research focuses on portrayal of the characteristics of persons, situations or groups (Polit \& Beck 2008:752). The purpose of descriptive research is to provide a detailed account of the phenomenon under study in order to understand the meaning of an experience (Burns \& Grove 2005:201). Descriptive research provides an in-depth description of participants' experiences in a narrative type description. The focus of this study was on the meanings given by PNPs to their experiences of working with MHCUs presenting with acute symptoms.

\section{Contextual design}

A contextual design is more concerned with making sense of human experience from within the context and perspective of their experiences (Terre Blanche \& Durrheim 1999:398). The researcher described the actions and experiences of PNPs in substantial detail. The aim was to describe and understand events within the concrete, natural context in which they occur. Babbie and Mouton (2001:272) maintain that if one understands the events against the background of the whole context and how such a context confers meaning to the events concerned, one can truly claim to understand the events. Asking PNPs about their experiences of working with MHCUs presenting with acute symptoms gave the researcher a better understanding of the phenomenon, against the background of PNPs' work environment.

\section{Population}

Parahoo (2006:256) defines population as the total number of units from which data can potentially be collected. The population in this study was PNPs working with MHCUs presenting with acute symptoms in a public mental health care institution in Gauteng. At the time of the study there were 82 PNPs working with these individuals.

\section{Sampling criteria}

Sampling is the process of selecting a portion of the population to represent the entire population (Polit \& Beck 2008:338). In this study a purposive sampling method was used. Purposive sampling involves the researcher in consciously selecting certain participants from whom he or she can learn about the issue which is the central focus of the study (Burns \& Grove 2005: 325).

Inclusion criteria for participating in this study were male or female registered PNPs who had more than one year's experience working in a public mental health care institution in Gauteng, and at the time of the study were working with MHCUs presenting with acute symptoms.

\section{Data collection method}

A research method is a technique used to structure a study and to gather and analyse data in a systematic way (Polit \& Beck 2008:765). In this study data were collected through focus group interviews. Morgan (cited in De Vos et al. 2005:306) defines focus group interviews as a data collection method through group interaction on the topic of interest. The researcher conducted four focus group interviews, each with 4-8 members and lasting 45-60 minutes, until data saturation was reached. The interviews were recorded to enable accurate, verbatim transcription. Participants were asked the following in-depth question: What are your experiences of working with mental health care users presenting with acute symptoms?

The researcher made use of drawings, naïve sketches and field notes for the purpose of data triangulation.

\section{Data analysis}

According to Polit and Beck (2008:507) data analysis is a process of organising, providing structure and eliciting meanings from research data. Verbatim transcription of the focus group interviews was done, drawing and naïve sketches were read and data were analysed in accordance with Tesch's method of open coding (cited in Creswell 2003:192).

\section{Ethical considerations}

The researcher asked permission from the particular public health care institution in Gauteng and sought ethical approval from the Research Ethics Committee of the University of Pretoria before conducting the study. The following ethical principles of the Belmont Report (Polit \& Beck 2008:170-175) were adhered to: beneficence, respect for human dignity, and justice.

\section{Beneficence}

The principle of beneficence encompasses a duty on researchers to minimise harm and maximize benefits (Polit 
\& Beck 2008:170). Participants had the opportunity to share their experiences about working with MHCUs presenting with acute symptoms. The researcher conducted the research process in a way to ensure that he did not cause any internal or external harm to participants, and was available to provide emotional support for those who may have experienced emotional discomfort. He had the contact details of a counsellor in the employee wellness department for referral if necessary.

\section{Respect for human dignity}

This includes the right to self-determination and full disclosure (Polit \& Beck 2008:172). Prospective participants were informed that participation was voluntary, that they had the right to decide to participate in the study as well as to withdraw from it at any time without risking any prejudicial judgement. The researcher provided potential participants with full information about the nature of the study. An information leaflet as well as a consent form were issued to all potential participants, describing the purpose, procedure and potential risks and benefits of the study. Participants signed the letter of consent after the content, purpose, procedure, potential risks and benefits had been explained to them.

\section{Justice}

Parahoo (2006:112) states that justice involves being fair to participants by not giving preferential treatment to some and depriving others of the attention they deserve. Selection of potential participants was open and fair, without any discrimination. PNPs who declined to participate in the study were not treated in a prejudicial manner. All data provided by the participants were kept in strictest confidence.

\section{Trustworthiness}

To ensure the trustworthiness of data collection and interpretation thereof, the framework as described by Lincoln and Guba (cited in Polit \& Beck 2008:539-540) was applied. This framework identifies the following five criteria for evaluating trustworthiness: credibility, confirmability, transferability, dependability and authenticity.

\section{Credibility}

Credibility refers to confidence in the truth of the data and in the researchers' interpretations of the data (Polit \& Beck 2008:539). In this study credibility was ensured through prolonged engagement, reflexivity, triangulation, member checking, a chain of evidence and the authority of the researcher.

\section{Confirmability}

Polit and Beck (2008:539) define confirmability as the potential for congruence between two or more independent people about the data's accuracy, relevance and meaning. The researcher involved an independent coder to assist with data analysis and ensure accuracy of the data.

\section{Transferability}

According to Polit and Beck (2008:539), transferability refers to the generalisability of the data, that is the extent to which findings from the data can be transferred to or have applicability in other settings or groups. The researcher used purposive sampling and provided a complete and thick description of the research setting and findings.

\section{Dependability}

Dependability refers to the stability of data over time and over conditions (Polit \& Beck 2008:539). An independent coder was involved to determine whether the procedures followed in the study were acceptable. The researcher further enhanced dependability by involving a research supervisor and a co-supervisor.

\section{Authenticity}

Authenticity is the extent to which the researcher fairly and faithfully shows a range of different realities (Polit \& Beck 2008:540). The researcher represented multiple realities of participants by conveying their life experiences in their natural context.

\section{Discussion of results Demographic profile of the sample}

Four focus group interviews which comprised of a total of 21 psychiatric nurse practitioners were included in the study. The first focus group interview consisted of seven psychiatric nurse practitioners, five females and two males between the ages 26 years and 50 years. The second constituted four psychiatric nurse practitioners, two males and two females between the ages of 28 years and 42 years. There were five psychiatric nurse practitioners, three females and two males between the ages of 26 years and 40 years, in the third focus group interview, whilst the fourth was made up of five psychiatric nurse practitioners, two males and three females aged between 26 years and 46 years.

Three themes concerning the experiences of psychiatric nurse practitioners working with MHCUs presenting with acute symptoms emerged from data analysis. The themes and categories are presented in Table1 and are followed by a narrative discussion.

\begin{tabular}{lll} 
TABLE 1: Overview of themes and categories. \\
\hline Themes & Description & Categories \\
\hline Theme 1 & $\begin{array}{l}\text { Experience of entering an } \\
\text { unsafe world where } \\
\text { care becomes a burden, } \\
\text { related to contextual challenges }\end{array}$ & $\begin{array}{l}\text { Behaviour and attitudes displayed } \\
\text { by MHCUs. } \\
\text { Behaviour and attitudes displayed } \\
\text { by doctors, managers and } \\
\text { security officers. } \\
\text { A context displaying limited } \\
\text { resources. }\end{array}$ \\
Theme 2 & $\begin{array}{l}\text { Negative emotional reactions } \\
\text { and attitudes towards } \\
\text { MHCUs that compromise } \\
\text { quality nursing care }\end{array}$ & $\begin{array}{l}\text { An overwhelming sense of fear and } \\
\text { being helpless. } \\
\text { Ineffective management of } \\
\text { emotional reactions. } \\
\text { Compromised quality of nursing } \\
\text { care. }\end{array}$ \\
& $\begin{array}{l}\text { A plea for a nurturing environment } \\
\text { that would enhance quality nursing } \\
\text { care }\end{array}$ & $\begin{array}{l}\text { Suggested attitudes, skills and } \\
\text { competencies displayed by } \\
\text { psychiatric nurses. } \\
\text { Organisational support. }\end{array}$ \\
\hline
\end{tabular}




\section{Central storyline}

The participants described working with the MHCUs as entering an unsafe world, where care became a burden, related to contextual challenges. They experienced negative emotional reactions and attitudes towards these users that compromised quality nursing care and made a plea for a nurturing working environment.

\section{Theme 1: Experience of entering an unsafe world}

The participants expressed working with MHCUs as an experience of entering an unsafe world. The following categories emerged within the theme of the participants' experience of entering an unsafe world:

- Behaviour and attitudes displayed by MHCUs

- Behaviour and attitudes displayed by doctors, management and security officers

- A context displaying limited resources.

\section{Behaviour and attitudes displayed by MHCUs}

The participants experienced that the MHCUs showed an attitude of disrespect towards them. Though the male participants experienced this disrespect to a certain extent, it seemed to be directed predominantly at the female participants.

\section{A female participant reported as follows:}

'They undermine the females especially over the weekend when they see that there are only two males and that maybe there are three females, then they start to behave wildly.'(Participant A, female, aged about 32 years)

In a study by Nijman, Bowers, Oud and Jansen (2005: 217-227) on psychiatric nurses' experiences with in-patient aggression using the Perceptions of Prevalence of Aggression Scale, it was found that psychiatric nurse practitioners, particularly females experienced sexual harassment. In the current study participants verbalised that female psychiatric nurse practitioners developed a fear of working with male MHCUs due to this kind of disrespectful sexual intimidation.

One female participant referred to the role that acute symptoms may play in the attitude of disrespect shown by the MHCUs. In her naïve sketch she mentioned that users who were psychotic tended to think of her as their girlfriend and, therefore, thought they could treat her in an intimate or casual way, and she became fearful of them.

\section{Behaviour and attitudes displayed by family, doctors, management and security officers}

The participants stated that they experienced the behaviour and attitudes displayed by family members of the MHCU as well as those of the doctors, management and security officers as unsupportive and unrealistic. They mentioned that this combined lack of support from the various stakeholders had a negative effect on their work - to such an extent that their work became a burden.

The participants stated that there was a lack of social and emotional support from family members of MHCUs. One participant said:
'I think our families play a major role and at some stage the families of the patient they are not so supportive.' (Partricipant $B$, male, aged about 35 years)

In a naïve sketch one participant explained that the relatives of MHCUs needed to be educated about the symptoms that MHCUs present with:

'Relatives of users, they need more or intensive health education about the mental health care user's symptoms.' (Participant C, male, aged about 35 years)

In the current study the participants stated that they experienced a lack of support and understanding from the families of MHCUs. They also concluded that the families lacked knowledge about mental illness. Results in a study by Nyati and Sebit (2002:208) on the burden of mental illness on family members showed that many family members did not offer support to MHCUs because of their lack of knowledge about mental illness.

The participants explained that, due to the staff shortage, it took more time than needed to admit a MHCU and attend to his or her family's queries simultaneously. The psychiatric nurse practitioners made a plea for support from the doctors, management and security officers.

The behaviour and attitudes displayed by the doctors, management and security officers added to the burden of care. One psychiatric nurse practitioner stated his experience with doctors as follows:

'Maybe I feel sometimes with acute patients tends to stay in the hospital, the doctor keeps them in hospital for a long time.' (Participant $\mathrm{D}$,female, aged about 30 years)

One participant wrote the following in the naïve sketch to reflect on the lack of support from colleagues and supervisors:

'The most difficult and challenging point is lack of support from colleagues, supervisors, families and the communities at large.' (Participant E, female, aged about 40 years)

According to the participants, they experienced it as challenging to work with MHCUs without significant support from colleagues and supervisors.

A study by Kindy, Peterson, and Parkhust (2005:172) on nurses' experience in psychiatric units with high risk of assault found that doctors were perceived to contribute to the risk of assault by not being supportive to psychiatric nurse practitioners.

The participants voiced that they experienced the behaviour and attitudes displayed by the doctors, management and security officers as unsupportive. It contributed to the burden of care of working with MHCUs presenting with acute symptoms. The burden of care was further exacerbated by the limited resources.

\section{A context displaying limited resources}

The participants reflected that the shortage of PNPs and limited number of closed wards added to the burden of nursing care. The shortage was mentioned by a participant: 
'We end up being three females with 36 patients.' (Participant $\mathrm{F}$,female, aged about 28 years)

Participants in the current study stated that staff shortages made it difficult to meet demands such as close monitoring and emotional support to MHCUs. Jenkins and Elliott (2003:626) studied stressors in an acute mental health setting, and found that the shortage of staff contributed to a higher workload and more stress for PNPs. An experience of stress may lead to PNPs experiencing a sense of helplessness.

According to Brennan, Flood and Bowers (2006:477) acute wards struggle to maintain the basic workforce, and this affects the quality of mental health user care. Participants in this study stated that the shortage of PNPs increased individual workloads, adding to the burden of care.

Another factor contributing to the burden of care was the shortage of closed wards. According to the participants there were not enough closed wards in the specific mental health care institution to cater for all the MHCUs. At the time of the study there were six closed wards with a total bed capacity of 141. The number of MHCUs frequently exceeded the bed capacity. To create an empty bed for newly admitted users some MHCUs were transferred to an open ward before they were stable enough to cope there. One participant said:

'And sometimes [due to the] lack of facilities, they stay for about a week in a closed ward and [are then] transferred to an open ward.' (Participant G, female, aged about 32 years)

In the mental health institution where this study was conducted, for example, one ward could accommodate 30 MHCUs on the basis of having 30 beds and seven PNPs providing care. If the number exceeded 30, it resulted in overcrowding. Overcrowding in a closed ward frequently resulted in competition for limited resources, which led to fights and arguments between the MHCUs.

The findings of the current study are supported by those of Currid (2009:43) on the experiences of stress amongst nurses in an acute mental health setting in London, where it was found that there was a shortage of beds and that demand outweighed availability.

A shortage of staff and inadequate number of closed wards made participants develop negative emotional reactions and negative attitudes towards MHCUs, thus also affecting their mental health negatively.

\section{Theme 2: Negative emotional reactions and attitudes towards MHCUs that compromise quality nursing care}

Participants experienced negative emotional reactions towards MHCUs because of the fear they developed for the users, combined with the fact that they felt helpless about it. The following subcategories emerged within the category of negative emotional reactions: an overwhelming sense of fear and being helpless; management of emotional reactions; and compromised quality of nursing care.

\section{An overwhelming sense of fear and being helpless}

Participants stated that they experienced a sense of fear and helplessness that was accompanied by frustration, ambivalence, guilt and feeling demotivated. MHCUs may present with aggressive behaviour and this can lead to PNPs experiencing fear of being injured by these users. One participant, whose facial expression showed fear as reflected in the field notes, stated the following:

'You feel that care users are unpredictable, that is where the issue of fear comes in.' (Participant $\mathrm{H}$,female, aged about 30 years)

As has been mentioned in the current study, a participant stated that she was once assaulted by an MHCU and that this caused her to work in fear. Similarly, in a study by Carlsson, Dahlberg, and Drew (2004:538) on violence and aggression in mental health nursing, it was found that PNPs who had encountered aggressive MHCUs on a previous occasion experienced fear and anxiety related to working with MHCUs.

As a result of working with MHCUs participants experienced mental tiredness, emotional distress and burnout. The field notes reflected that one participant's face held a hopeless expression as she described her exhaustion:

'You cannot get out of bed, you just feel burned out, you have got nothing to do, and you are demotivated.' (Participant I, female, aged about 42 years)

The same participant explained that PNPs felt that although they gave a lot of themselves emotionally and physically when working with MHCUs, they received nothing in return:

'... you are not only dealing with, emotionally dealing with the patient, you are also dealing with the family and they are also emotional being, you are an emotional being, the patient is an emotional being, so that makes it, that makes it hard ...' (Participant I, female, aged about 42 years)

For the participants it was a challenge to be emotionally available to MHCUs and their families. What made it worse was that the needs of MHCUs presenting with acute symptoms were more complex compared to those of other MHCUs.

According to Sadock and Sadock (2007:489) MHCUs may suffer from psychosis that includes hallucinations, delusion, or suspiciousness. The acute symptoms are supported by emotional instability and feelings of anger, and can be projected towards PNPs in a verbal or physical manner. Some participants mentioned feeling demotivated and exposed to work stress.

The participants working with MHCUs revealed that they felt demotivated and experienced burnout. This could lead to the ineffective management of emotional reactions, that ultimately compromises quality nursing care.

\section{Ineffective management of emotional reactions by PNPs}

It was stated by the participants that they ended up managing emotional reaction ineffectively through suppression of emotions. Feelings of fear and anger were suppressed: 
'I think you learn to suppress it [fear] in a way, ... whether this is healthy or not.' (Participant J, female, aged about 32 years)

In one naïve sketch a participant expressed the following about managing emotional reactions:

'You feel angry but within a minute you have to take the anger away.' (Participant J, female, aged about 32 years)

Moran et al. (2009:599) concluded in their study that working in an area with a high level of aggression and violence forced PNPs to suppress their emotions in an effort to do their job. Participants in the current study expressed that they experienced emotional reactions like fear and anger, but tried not to acknowledge such emotional reactions by suppressing them.

Dealing with fear and anger by suppressing emotions is not conducive to mental health. Ongoing suppression may jeopardise the PNPs' morale and mental well-being.

\section{Compromised quality of nursing care}

To protect themselves the participants withdrew from caring activities and interaction with the MHCUs, as evidenced in the following:

'Once a patient becomes displaying sexually inappropriate behaviour we end up shutting him down even when he comes for something else.' (Participant $\mathrm{K}$, female, aged about 50 years)

When MHCUs needed help, participants withdrew from caring activities, using the MHCUs' past psychiatric symptoms as a frame of reference. This is evidenced by the following written in a naïve sketch:

'They need attention most of the time, they always complain daily.' (Participant K, female, aged about 50 years)

When MHCUs expressed their unmet needs, participants seemed to interpret this expression as daily complaint, thus compromising nursing care. Findings by Higgins, Barker and Begley (2008: 616,620) on the nursing discourse in relation to MHCUs who present with unacceptable sexual behaviour were that PNPs tended to ignore them. In the current study participants stated that if an MHCU had a history of presenting with inappropriate sexual behaviour, they became inclined to withdraw from the particular user.

Participants in this study acquiesced that quality nursing care was compromised because they found it a challenge to establish a therapeutic relationship with MHCUs. They experienced a feeling of quilt for not fulfilling their role of caretakers in the treatment and rehabilitation of MHCUs. They pleaded for a nurturing environment.

\section{Theme 3: A plea for a nurturing environment that would enhance quality nursing care}

Participants made a plea for a nurturing environment that would enhance quality of nursing care through the promotion of milieu therapy. They expressed a need to develop positive attitudes towards MHCUs through skills and competency development, and organisational support from management. The following categories emerged within the theme of participants' plea for a nurturing environment: suggested attitudes, skills and competencies displayed by PNPs; and organisational support.

\section{Suggested attitudes, skills and competencies displayed by PNPs}

To enhance quality of nursing care participants suggested developing a positive attitude towards MHCUs. They also expressed a need to develop skills and competencies. Participants verbalised that they should display positive attitudes towards MHCUs. They thought that it was important to strive towards developing an attitude of respect as well as good listening skills. One participant emphasised the significance of a positive attitude:

'My attitudes towards them must be very positive the very first day, the first time I meet them.' (Participant L, male, aged about 30 years)

Showing an attitude of respect is essential, as MHCUs who are respected in turn show respect for the PNPs. Participants in the current study reflected that attitudes towards MHCUs should be positive during the first contact. Björkman, Angelman and Jönsson (2008:170) conducted a study on attitudes towards people with mental illness, and concluded that health professionals should develop positive attitudes towards MHCUs. An attitude of respect can be achieved through therapeutic communication skills.

Participants made suggestions regarding attitudes, skills and competencies displayed by PNPs to enhance quality nursing care. A need was verbalised for participants to develop their attitudes, skills and competencies. In the PNPs' opinion these could be enhanced by organisational support through mentoring of the management of emotions whilst working with MHCUs.

\section{Organisational support to PNPs}

Participants made a plea for organisational support in terms of emotional support for staff in the form of debriefing or acknowledgement by word of mouth that they had done a good job. In addition, participants said they required mentoring as they thought they lacked sufficient knowledge and skills to work with MHCUs.

A need for emotional support from management in the form of debriefing was expressed by the participants. Emotional support would enhance PNPs' maintaining their mental health status, as noted by one participant:

'And we also need support system from work.' (Participant M, female, aged about 26 years)

Participants also stated that they needed therapy to help them cope with the challenges of working with MHCUs:

'Once you work with these people you should go for therapy regularly, in any way you know just to debrief what you are feeling.' (Participant $\mathrm{N}$ female, aged about 32 years)

The need for psychological support to PNPs is supported by Chen, Hwu and Williams (2005:141-149). Referring to their study on PNPs' anxiety and cognition in managing MHCUs, 
Chen et al. (2005:146) suggest that psychological support in the form of debriefing will help PNPs to cope with aggressive incidents when working with MHCUs.

Exposure of PNPs to violence by MHCUs may negatively affect the former's mental health. Therefore PNPs receiving emotional support in the form of debriefing will enhance the quality of care they provide to MHCUs.

Participants made a plea for a nurturing environment to improve quality of care to MHCUs in the form of debriefing to enhance their mental health. The need for emotional support can be linked to the need for mentoring requested by participants. According to Zauszniewski (2009:113), mentorship involves an experienced PNP who guides mentees in development and examination of their own personal growth and professional development. As revealed in this study, mentorship will equip the less experienced PNPs with skills to take care of MHCUs with confidence.

Mentoring of PNPs can increase their knowledge and skills, create a nurturing environment, and affect their mental health positively.

\section{Limitations of the study}

Two limitations were identified in this study. The research was conducted in a specific public mental health care institution in Gauteng. There is a need for further research in other geographical areas to compare the results. The research was also focused on PNPs with more than one year's experience of working with MHCUs presenting with acute symptoms. Other categories of nurses might have different experiences due to differences in skills or scope of practice. Further research in different staff categories is needed.

\section{Recommendations}

Recommendations proposed on the basis of the results of this study focus on nursing practice, research and education.

\section{Nursing practice}

The advanced PNP, through use of the theory for health promotion in nursing (University of Johannesburg 2009:216) should aim to facilitate the mental health of PNPs by mobilising the internal and external resources to promote nursing practice. The advanced PNP should empower the PNP to work in accordance with existing policies and high ethical standards to protect the rights of MHCUs presenting with acute symptoms. She or he should ensure that PNPs have access to information about procedures related to nursing practice, and that they practice according to standards set by statutory bodies like the South African Nursing Council, and in accordance with the existing Mental Health Care Act.

\section{Nursing research}

The advanced PNP should mobilise resources to promote evidence-based practice. She or he should encourage PNPs to participate and be involved in research. The advanced PNPs should promote PNPs' access to research reports related to working with MHCUs presenting with acute symptoms, based on clinical experience supported by research.

\section{Nursing education}

The advanced PNP should mobilise resources to promote an atmosphere of training and learning. He or she should motivate, encourage and make learning resources available for PNPs. The advanced PNP should encourage PNPs to participate in in-service training, short courses and academic programmes related to working with MHCUs presenting with acute symptoms. The course contents should include skills of working with MHCUs presenting with symptoms of hallucinations and delusion, and managing MHCUs presenting with acute symptoms who display violent behaviour and unacceptable sexual behaviour.

\section{Conclusion}

The PNPs described working with MHCUs presenting with acute symptoms as entering an unsafe world where care became a burden, related to contextual challenges. They experienced negative emotional reactions and attitudes towards these users, that compromised quality of nursing care, and made a plea for a nurturing working environment. The advanced PNP needs to mobilise internal and external resources to facilitate the mental health of these PNPs.

\section{Acknowledgements}

I would like to express my sincere appreciation towards the following people and institution: Mrs Suzette Swart for the professional editing, Dr R.G. Visagie for data analysis and coding, Dr Neo Morojele for her support and encouragement, my colleagues for their support and encouragement, and the management and staff of the institution where the study was conducted

\section{Competing interests}

The authors declare that they have no financial or personal relationship which may have inappropriately influenced them in writing this article.

\section{Authors' contributions}

J.K.N. (University of Pretoria \& South Africa Medical Research Council) was a Master's candidate, E.v.R. (University of Pretoria) was a Supervisor, and S.M. (University of Pretoria) was a co-supervisor.

\section{References}

Babbie, E. \& Mouton, J., 2001, The practice of social research.: Oxford University Press, Cape Town, South Africa.

Bimenyimana, E., Poggenpoel, M., Myburg, C. \& Van Niekerk, V., 2006, 'The lived experience by psychiatric nurses of aggression and violence from patients in a Gauteng psychiatric institution', Curationis, 32(3), 4-13. 
Björkman, T., Angelman, T. \& Jönsson, M., 2008, 'Attitudes towards people with mental illness: A cross-sectional study among nursing staff in psychiatric and mematic care', Scand Journal of Caring Science, 22, 170-177. http://dx.doi. somatic care', Scand Journal of Caring Science, 22,
org/10.1111/j.1471-6712.2007.00509.x, PMid:18489686

Bowling, A., 2002, Research methods in health: Investigating health and health services, 2nd edn., Open University Press, Philadelphia.

Brennan, G., Flood, C. \& Bowers, L., 2006, 'Constraints and blocks to change and improvement on acute psychiatric wards: lessons from the city nurses project', Journal of Psychiatric and Mental Health Nursing 13, 475-482. http://dx.doi. org/10.1111/j.1365-2850.2006.00956.x, PMid:16965464

Burns, N.A. \& Grove, K.S., 2005, The practice of nursing research: Conduct, critique and utilisation, 5th edn., W.B. Saunders, Philadelphia.

Carlsson, G., Dahlberg, K. \& Drew, N., 2004, 'Encountering violence and aggression in mental health nursing: A phenomenological study of tacit caring knowledge', Issues in Mental Health Nursing 21(5), 533-545.

Chaplin, R., McGeorge, M. \& Lelliott, P., 2006, 'The national audit of violence: Inpatient care for adults of working age', Psychiatric Bulletin 30, 444-446. http:// dx.doi.org/10.1192/pb.30.12.444

Chen, S.C., Hwu H.G., H. \& Williams, R.A., 2005, 'Psychiatric nurses' anxiety and cognition in managing psychiatric patients' aggression', Archives of Psychiatric Nursing 19(3),143-149.

Clearly, M., 2003, 'The challenges of mental health care reform for contemporary mental health nursing practice: Relationships, power and control, International Journal of Mental Health Nursing 12, 139-147. http://dx.doi. org/10.1046/j.1440-0979.2003.00280.x, PMid:12956025

Creswell, J.W., 2003, Research design: Qualitative, quantitative and mixed methods approach, 2nd edn., Sage Publication, London.

Currid, T., 2009, Experiences of stress among nurses in acute mental health settings, Nursing Standard 23(44), 40-46.

Deacon, M., Warne, T. \& McAndrew, S., 2006, 'Closeness, chaos and crisis: The attractions of working in acute mental health care', Journal of Psychiatric Mental attractions of working in acute mental health care', Journal of Psychiatric Mental Health Nursing 13,7
PMid:17087679

De Vos, A., Strydom, H., Fouché C.B. \& Delport, C.S.L., 2005, Research at grass roots for the social sciences and human service professions, 3rd edn., Van Schaik for the social scien
Publishers, Pretoria.

Fourie, W.J., McDonald, S., Connor, J. \& Barlett, S., 2005, The role of the registered nurse in an acute mental health inpatient setting in New Zealand: Perceptions versus realit, International Journal of Mental Health nursing 14, 134-141. http:// versus realit, International Journal of Mental Health nursing 14,

Higgins, A., Barker, P. \& Begley, C. M., 2008, 'Clients with mental health problems who sexualize the nurse-client encounter: The nursing discourse', Journal of Advanced Nursing 65(3), 616-624. http://dx.doi.org/10.1111/j.1365-2648.2008.04899.x Nursing 65(3),

Humpel, N. \& Caputi, P., 2001, 'Exploring the relationship between work stresses, years of experience and emotional competency using a sample of Australian mental health nurses', Journal of Psychiatric and Mental Health Nursing 8 399403. http://dx.doi.org/10.1046/j.1365-2850.2001.00409.x, PMid:11882159

Jenkins, R. \& Elliott, P., 2003, 'Stressors, burnout and social support', Journal of Advanced Nursing 48(6), 622-631. http://dx.doi.org/10.1111/j.1365-2648.2004.03240.x, PMid:15548253
Kindy, D., Petersen, S. \& Parkhust, D., 2005, 'Perilous work: Nurses' experiences in psychiatric units with high risks of assault', Archives of Psychiatric Nursing, 19(4) 169-175. http://dx.doi.org/10.1016/j.apnu.2005.05.002, PMid:16088855

Mackay, I., Paterson, B. \& Cassels, C., 2005, 'Constant or special observation of inpatients presenting a risk of aggression or violence: Nurses' perception of the rules of engagement', Journal of Psychiatric and Mental Health Nursing, 12, 464-471. http://dx.doi.org/10.1111/j.1365-2850.2005.00867.x, PMid:16011502

Moran, A., Cocoman, A., Scott, P.A., Matthews, A., Staniuliene, V. \& Valimaki, M., 2009, 'Restrain and seclusion: A distressing treatment option?', Journal of Psychiatric and Mental Health Nursing, 16, 599-605. http://dx.doi.org/10.1111/j.13652850.2009.01419.x, PMid:19689553

Munro, S. \& Baker, J.A., 2007, 'Surveying the attitudes of acute mental health nurses', Journal of Psychiatric and Mental Health Nursing, 14, 196-202. http://dx.doi. org/10.1111/j.1365-2850.2007.01063.x, PMid:17352783

Nijman, H., Bowers, L., Oud, N. \& Jansen, G., 2005, 'Psychiatric nurses' experiences with inpatient aggression', Aggressive Behaviour, 31, 217-227. http://dx.doi. org/10.1002/ab.20038

Nyati, Z. \& Sebit, M.B., 2002, 'Burden of mental illness on family members, care-givers and the community', East African Medical Journal, 79(4), 206-209. http://dx.doi org/10.4314/eamj.v79i4.8880, PMid:12625678

Parahoo, K., 2006, Nursing research: Principles, process and issues, 2nd edn., Palgrave Macmillan, New York.

Polit, D.F. \& Beck, C.T., 2008, Nursing research: Generating and assessing evidence for nursing practice 8th edn., Lippincott, Williams \& Wilkins, Philadelphia.

Richards, D.A., Bee, P., Barkham, M., Gilbody, S.M., Cahill, J. \& Glanville, J., 2006 'The prevalence of nursing staff on adult acute psychiatric in-patient wards: A systematic review', Social Psychiatry and Epidemiology, 41, 34-43. http://dx.doi. org/10.1007/s00127-005-0998-7,PMid:16341829

Robinson, J.I., Clements, K.L. \& Land, C., 2003, 'Workplace stress among psychiatric nurses: Prevalence, distribution, correlates and predictors', Journal of Psychosocial Nursing, 41(4), 33-41.

Sadock, B.J. \& Sadock, V.A., 2007, Kaplan \& Sadock's synopsis of psychiatry: Behavioural Sciences/Clinical Psychiatry, 10th edn., Lippincott \& Wilkins, London.

Soanes, C., Hawker, S. \& Elliott, J, 2006, Oxford English Dictionary., 2006, 6th edn., Oxford, Oxford University Press.

South African Government. Mental Health Care Act, No. 17 of 2002. Government Printer, Pretoria.

Terre Blance, M. \& Durrheim, K., 1999, Research in practice, University of Cape Town Press, Cape Town

Theodoridou, C., Bowers, L., Brennan, G., Gilbert, D. \& Winship G., 2009, 'The measurement of psychotic acuity by nursing staff', Journal of Psychiatric and Mental Health Nursing, 16, 234-241.http://dx.doi.org/10.1111/j.13652850.2008.01338.x, PMid:19291151

Uys, L. R. \& Middleton, L., 2010, Mental health nursing: A South African perspective, 5 th edn., Juta, Cape Town.

University of Johannesburg, 2009, The Theory of Health Promotion, Department of Nursing Science Paradigm, University of Johannesburg, Auckland Park.

Waldheter, E.J., Nicole, T., Johnson, E.R. \& Penn, D.L., 2005, 'Utility of social cognition and insight in the prediction of inpatient violence among individuals with a severe mental illness', The Journal of Nervous and Mental Disease, 193(9), 609-618. http://dx.doi.org/10.1097/01.nmd.0000177788.25357.de, PMid:16131944

Zauszniewski, J.A., 2009, 'Mentoring our next generation: Time to dance', Journal of Advanced Psychiatric Nursing, 22(3), 113-114. 